\title{
An Oxalate-Bridged Binuclear Iron(III) Ionic Liquid for the Highly Efficient Glycolysis of Polyethylene Terephthalate under Microwave Irradiation
}

\author{
Sergi Cot, ${ }^{\S}$ Meike K. Leu, ${ }^{\dagger}$ Alexis Kalamiotis, ${ }^{\S}$ Dr. Georgios Dimitrakis, ${ }^{\S}$ Dr. Victor

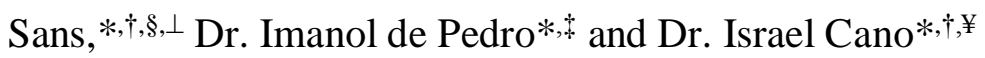

† GSK Carbon Neutral Laboratory for Sustainable Chemistry, University of Nottingham, NG7 2GA, Nottingham, UK

\author{
$\S^{\S}$ Faculty of Engineering, University of Nottingham, NG7 2RD, Nottingham, UK \\ $\ddagger$ CITIMAC, Facultad de Ciencias, Universidad de Cantabria, 39005 Santander, Spain \\ ${ }^{¥}$ School of Chemistry, University of Nottingham, NG7 2RD, Nottingham, UK \\ ${ }^{\perp}$ Institute of Advanced Materials (INAM), Universitat Jaume I, 12006, Castellon, Spain \\ *Corresponding Authors: victor.sanssangorrin@nottingham.ac.uk(Victor Sans); \\ depedrovm@unican.es (Imanol de Pedro); israel.canorico@nottingham.ac.uk (Israel Cano)
}

Supporting Information for this article is given via a link at the end of the document.

ABSTRACT: A new oxalate-bridged binuclear iron(III) ionic liquid combined with an imidazolium based cation, (dimim $)_{2}\left[\mathrm{Fe}_{2} \mathrm{Cl}_{4}(\mu\right.$-ox $\left.)\right]$, was synthesized and characterized by a wide range of techniques. This halometallate ionic liquid was active catalysing the depolymerization by glycolysis of polyethylene terephthalate (PET), under conventional and microwave-assisted heating conditions. Both methodologies were very selective towards the production of bis(2-hydroxyethyl)terephthalate (BHET). The employment of microwave heating proved beneficial in terms of time and energy saving when compared to the use of thermal heating. Indeed, dielectric spectroscopy studies revealed that the binuclear iron-containing ionic liquid exhibits an excellent heating response under an electromagnetic field. The catalyst provided quantitative conversions to BHET in the glycolysis of post-consumer PET bottles in only $3 \mathrm{~h}$ through microwave heating, as compared to $80 \%$ conversion after $24 \mathrm{~h}$ under conventional heating.

Keywords: Glycolysis; ionic liquids; iron; microwave irradiation; poly(ethylene terephthalate).

\section{INTRODUCTION}

The annual production of plastics is around 311 million metric tons. ${ }^{[1]}$ Poly(ethylene terephthalate) (PET) is one of the most important plastics, since this versatile polymer is non-toxic, odourless, tasteless and exhibits excellent physical and chemical properties, such as thermal stability, mechanical and 
chemical resistance, high transparency and clarity. ${ }^{[2]}$ As a consequence, this polymeric material has shown numerous applications, ${ }^{[2]}$ leading to a worldwide production of more than 50 million tons every year. ${ }^{[1]}$ However, only a small fraction of PET produced annually is recycled, thus constituting a problem from an environmental protection standpoint since this polymer degrades very slowly. ${ }^{[3]}$ There are four different approaches for PET recycling: in plant, chemical, mechanical and energy recycling. ${ }^{[2,4]}$ Chemical recycling involves the partial or total depolymerization of PET into its components (monomers, oligomers and other chemicals), following the rules of "sustainable development". ${ }^{[2]}$ Common depolymerization routes employed for chemical recycling of PET are methanolysis, hydrolysis, glycolysis, aminolysis, ammonolysis and hydrogenation, among others. ${ }^{[5]}$ Glycolysis of PET to BHET monomer (bis(2-hydroxyethyl) terephthalate) is typically done employing a glycol (i.e., ethylene glycol, EG), high temperatures and a transesterification catalyst. ${ }^{[5]}$ This transformation has been reported using a wide variety of catalysts, including metal salts, ${ }^{[5]}$ nanocomposites ${ }^{[2]}$ metal oxides, ${ }^{[4]}$ metal oxide nanoparticles, ${ }^{[5]}$ urea, ${ }^{[6]}$ castor oil ${ }^{[7]}$ and enzymes. ${ }^{[7]}$ Ionic liquids ${ }^{[8]}$ and deep eutectic solvents ${ }^{[9]}$ are interesting options that have been proposed in recent times. Specifically, ionic liquid (IL) properties make them ideal catalysts for this process due to their optimal thermal stability, negligible vapour pressure and high catalytic activity. ${ }^{[2-6,10-11]}$ Imidazolium based metal-containing ILs with Lewis acid properties perform this transformation efficiently. They operate as a bifunctional catalyst in which the imidazolium cation acts as Lewis acid and the metal anion as a nucleophile. ${ }^{[12]}$ However, only a few examples have been reported where imidazolium based metal-containing ILs were employed for the glycolysis of PET. ${ }^{[12]}$

Looking for novel imidazolium and halometallate type ILs with a proficient potential as catalysts for PET glycolysis, we devised the synthesis of a binuclear complex as an alternative to the mononuclear halometallate-based ILs employed to date, since the former have proved to be better catalysts under microwave heating due to their dielectric heating properties. ${ }^{[13]}$ In this context, the oxalate group $\left(\left(\mathrm{C}_{2} \mathrm{O}_{4}\right)^{2-}\right.$ or ox $)$ is an ambidentate ligand that presents a very rich coordination chemistry. The bischelating coordination mode is the most interesting one because it facilitates the formation of a great diversity of mineral ${ }^{[14]}$ and homo- and hetero-metallic multifunctional materials ${ }^{[15]}$ (including molecular magnetic conductors, superconductors and stimuli-responsive magnetic materials) with interesting properties such as magnetism, electrical conductivity, optical or catalytic activity. ${ }^{[16]}$ A common feature of these structures is the presence of hydrogen-bond, $\pi-\pi$, or other weak interactions, which contribute to the cohesion of the structures. These structures are negatively charged and therefore can be combined with functional molecular cations in order to afford new multifunctional materials. Inspired by these works, herein we report the synthesis of a novel oxalate-bridged binuclear iron(III) ionic liquid based on imidazolium cation, $(\operatorname{dimim})_{2}\left[\mathrm{Fe}_{2} \mathrm{Cl}_{4}(\mu\right.$-ox) $]$ (dimim= 1,3 dimethylimidazolium), through a straightforward route that allows its large-scale preparation. The catalytic activity of this imidazoliumbased halometallate complex was studied in the degradation of PET, which enabled us to investigate its 
performance under conventional and microwave-assisted heating conditions and compare both methodologies. To the best of our knowledge this is the first case which describes the synthesis and catalytic application of an oxalate-bridged paramagnetic ionic liquid.

ILs, being in essence molten salts with a melting point below $100{ }^{\circ} \mathrm{C}$, generally exhibit very strong microwave heating properties. ${ }^{[17]}$ The interaction of ILs with a microwave field is underpinned by their dielectric properties. The dielectric properties of a material are described by the value of the complex permittivity $\left(\varepsilon^{*}\right),{ }^{[18]}$ which consists of a real component $\left(\varepsilon^{\prime}\right)$, for convenience often termed dielectric constant $\left(\varepsilon^{\prime}\right)$, and an imaginary component termed dielectric loss $\left(\varepsilon^{\prime \prime}\right) . \varepsilon$ determines the amount of energy that can be stored by a material in the presence of an electromagnetic field, whereas $\varepsilon$ ' denotes the amount of the stored energy that can be converted into heat. Both $\varepsilon^{\prime}$ and $\varepsilon^{\prime \prime}$ are functions of temperature and frequency. In the present work, we have studied the dielectric properties of $(\operatorname{dimim})_{2}\left[\mathrm{Fe}_{2} \mathrm{Cl}_{4}(\mu\right.$-ox $\left.)\right]$ in order to ascertain its response under microwave frequencies and determine the contribution of the iron-containing IL in the context of its heating behavior during the glycolysis process.

\section{RESULTS AND DISCUSSION}

\section{Synthesis and characterization of oxalate-bridged binuclear iron(III) ionic liquid based on imidazolium cation (dimim) $)_{2}\left[\mathrm{Fe}_{2} \mathrm{Cl}_{4}(\mu-\mathrm{ox})\right]$}

The imidazolium based iron-containing ionic liquid (dimim) $)_{2}\left[\mathrm{Fe}_{2} \mathrm{Cl}_{4}(\mu\right.$-ox $\left.)\right](3)$ was prepared by a three step synthetic strategy (Scheme 1, for further details see Experimental Section). 1,3Dimethylimidazolium iodide (dimim)I was eluted with water through an ion exchange resin column (Amberlite IRA, basic form) to give 1,3-dimethylimidazolium hydroxide (dimim)OH (1), which was subsequently reacted with oxalic acid to provide the oxalic-based IL (dimim) $)_{2} \mathrm{Ox}(\mathbf{2})$. Then, $\mathbf{2}$ was treated in situ with $\mathrm{FeCl}_{3}$ at room temperature (R.T.) to afford 3.

1)

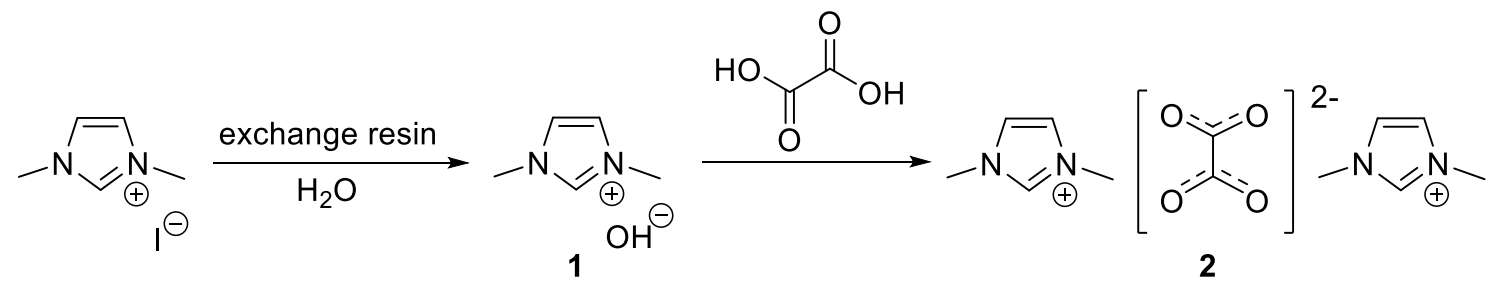

2)

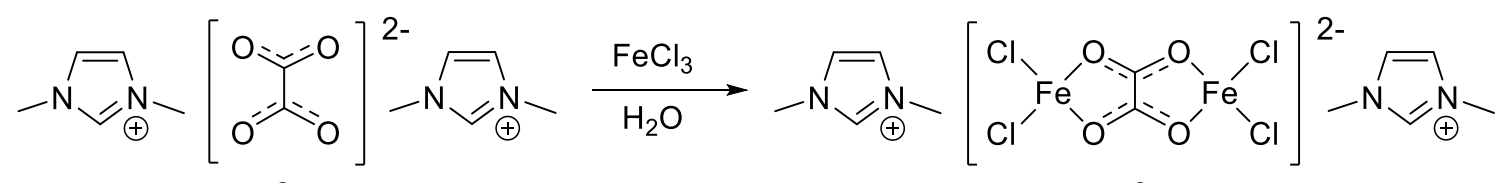

2

3

Scheme 1. Formation of (dimim) $)_{2}\left[\mathrm{Fe}_{2} \mathrm{Cl}_{4}(\mu\right.$-ox $\left.)\right](3)$. 
Due to the paramagnetic nature of the sample, nuclear magnetic resonance (NMR) is not a suitable spectroscopic tool to characterize iron-containing ionic liquids. Moreover, in contrast with our previous work about PET depolymerisation by imidazolium-based halometallate complexes, ${ }^{[13]}$ we were not able to obtain single crystals suitable for X-ray diffraction analysis. Therefore, $(\operatorname{dimim})_{2}\left[\mathrm{Fe}_{2} \mathrm{Cl}_{4}(\mu\right.$-ox $\left.)\right]$ was fully analysed by the use of a wide variety of techniques, including elemental analysis (EA), thermogravimetric analysis (TGA), inductively coupled plasma optical emission spectrometry (ICPOES), differential scanning calorimetry (DSC), Fourier-Transform Infrared (ATR FT-IR) and Raman spectroscopies, magnetic measurements, and dielectric spectroscopy studies.

ICP gave an iron content of $c a .20 .2 \%$, which is in good agreement with the expected value $(20.1 \%)$, whereas TGA showed that the reproducibility is high (ca. 19.4\%, see Figure S1, Supporting Information). In addition, EA was consistent with the calculated contents of $\mathrm{C}, \mathrm{N}$ and $\mathrm{H}$ (for further details see Experimental Section). DSC (Figure S2, Supporting Information) did not show solid-solid (s-s) phase transitions upon cooling the complex from above the melting point $\left(74{ }^{\circ} \mathrm{C}\right)$, which starts to decompose at about $250^{\circ} \mathrm{C}$ (Figure S1).

The iron complex $\mathbf{3}$ was investigated in detail by Raman and IR spectroscopies, since these techniques are extremely useful for studying the bonding and type of imidazolium compounds ${ }^{[19]}$ and the metal coordination environments of halometallates species. ${ }^{[20]}$ Figure 2 displays the non-polarized Raman and FT-IR spectra of 3 in the range of $150-3900 \mathrm{~cm}^{-1}$ at $300 \mathrm{~K}$. The vibrational assignments proposed herein are based on the comparison of spectroscopic behavior of the "free" oxalate anion ${ }^{[21]}$ with the data described in the literature for iron oxalate complexes ${ }^{[22]}$ and those published in our previous study of (dimim) $\left[\mathrm{FeCl}_{4}\right]$ complex (Table S1, Supporting Information). ${ }^{[23]}$ The tetrachloridoferrate (III) ion in tetrahedral (Td) coordination exhibits vibrational spectra characterized in the low-frequency region by four Raman-active vibration modes. ${ }^{[22]}$ According to the proposed structural formula for the metal complex $\left[\mathrm{Fe}_{2} \mathrm{Cl}_{4}(\mu-\mathrm{ox})\right]^{2-}$, which will display an identical structure in the plane as that depicted in Figure 1 in Td symmetry, such an anion presents four $\mathrm{Fe}-\mathrm{Cl}$ Raman-active vibration modes; two of them are attributed to the bending modes $\left[v_{\mathrm{s}}=111\right.$ and $\left.v_{\mathrm{as}}=137 \mathrm{~cm}^{-1}\right]$, while the others are related to the stretching modes $\left[v_{\mathrm{s}}=332\right.$ and $\left.v_{\mathrm{as}}=376 \mathrm{~cm}^{-1}\right]$ (Table S1).<smiles></smiles>

Figure 1. Schematic drawing of the anion composition in the presented compound.

These bands are shifted to higher energies as a result of the substitution of chlorine by oxygen atoms in $\mathrm{Td}$ symmetry. An estimation of vibration bending and stretching modes for the $\mathrm{Fe}-\mathrm{O}$ bond can be 
performed on the basis of the Raman shifts corresponding to the $\mathrm{Fe}-\mathrm{Cl}$ bond. ${ }^{[24]}$ The Raman frequency can be described approximately by the equation (1),

$$
v=\frac{1}{2 \pi} \sqrt{\frac{\kappa}{\mu}}
$$

in which $\kappa$ and $\mu$ are the bond strength and the reduced mass, respectively. Taking into account the difference between the atomic weight of $\mathrm{Cl}$ and $\mathrm{O}$ atoms, the Raman frequencies of $\left[\mathrm{Fe}_{2} \mathrm{OxCl}_{6}\right]^{2-}$ metal complex can be scaled as $v \mathrm{Fe}-\mathrm{O}=v \mathrm{Fe}-\mathrm{Cl} / 1.51$ assuming constant bond strengths. Thus, the estimated values obtained for the $\mathrm{Fe}-\mathrm{O}$ bond are $\left[v_{\mathrm{s}}=167\right.$ and $\left.v_{\mathrm{as}}=207 \mathrm{~cm}^{-1}\right]$ and $\left[v_{\mathrm{s}}=501\right.$ and $\left.v_{\mathrm{as}}=567 \mathrm{~cm}^{-1}\right]$ for the bending and stretching modes, respectively, which is consistent with the experimental data (Table S1 and figure 2a). Additionally, the Raman and IR spectra display vibration modes at ca. 416, 450 and $473 \mathrm{~cm}^{-1}$ corresponding to the $\delta \mathrm{O}-\mathrm{C}=\mathrm{O}$ and $\delta$ ring of oxalate bridge. ${ }^{[21,22,25]}$ Furthermore, the vibrational spectra of $\mathbf{3}$ feature the characteristic symmetric and antisymmetric $\mathrm{C}=\mathrm{O}$ stretching bands in the vicinity of 1302 and $1605 \mathrm{~cm}^{-1}$ (Table $\mathrm{S} 1$ and figure 2a). Hence, the observed fingerprint for the oxalate-bridged binuclear iron(III) complex is in good agreement with the reported literature. ${ }^{[22,25]}$

We have also compared the Raman and IR spectra of $\mathbf{3}$ to those of (dimim) $\left[\mathrm{FeCl}_{4}\right]$ in the region where the bands corresponding to imidazolium moiety appears, ${ }^{[23]}$ thus confirming the presence of this cation in the Fe-based IL. Both IR and the Raman spectra show three bands at $600-1550 \mathrm{~cm}^{-1}$ assigned to $\mathrm{CH}_{3}$ $\left(\mathrm{CH}_{3}-\mathrm{N}\right.$ and $\mathrm{H}-\mathrm{C}-\mathrm{H}$ stretching absorption, figure $\left.2 \mathrm{a}\right)$. The Raman spectrum also displays two weak bands at 3110 and $3164 \mathrm{~cm}^{-1}$ recognized as $\mathrm{H}^{-} \mathrm{C}-\mathrm{H}$ asymmetric stretch of $\mathrm{CH}_{3}$ (Figure $2 b$ ). ${ }^{[19,23]}$ Finally, the IR spectrum showed a broad band centered around $3450 \mathrm{~cm}^{-1}$, identified as the $\mathrm{H}_{2} \mathrm{O}$ stretching motion. On the basis of IR and Raman studies, we proposed that the metal cations and oxalate groups generate an arrangement in which the oxalate groups act as tetradentate bridging ligands, leading to a molecular formula $\left\{(\operatorname{dimim})_{2}\left[\mathrm{Fe}_{2} \mathrm{Cl}_{4}(\mu-\mathrm{ox})\right] \cdot \mathrm{H}_{2} \mathrm{O}\right\}$ n with one hydration $\mathrm{H}_{2} \mathrm{O}$ molecule, in good agreement with ICP and EA data. 

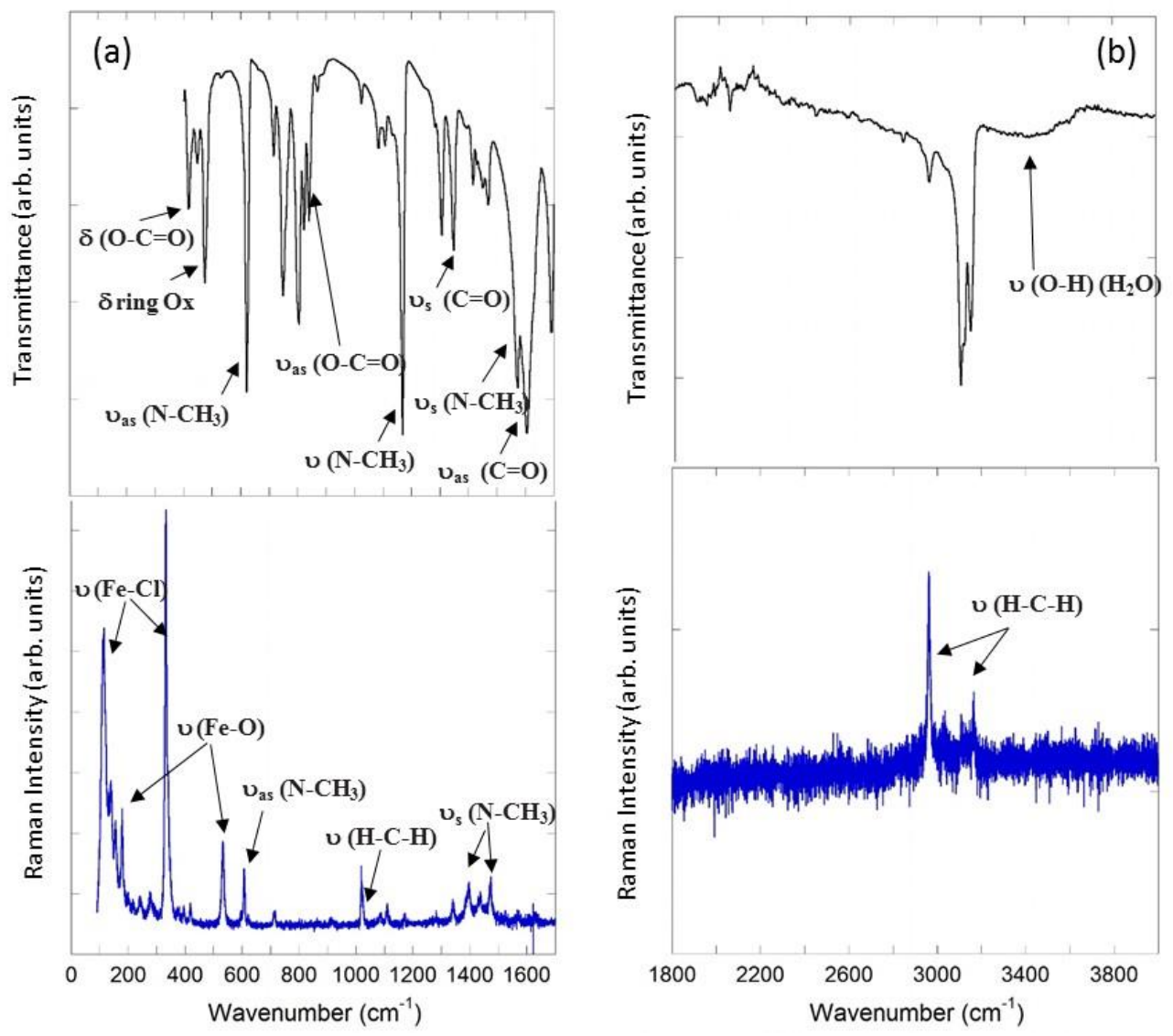

Figure 2. FT-Infrared (above) and Raman spectra (below) in the spectral range between (a) 150-1700 $\mathrm{cm}^{-1}$ and (b) $1800-3900 \mathrm{~cm}^{-1}$.

In addition, the magnetic properties of 3 were determined over the temperature range $2-300 \mathrm{~K}$ (for further details see Section 3, Supporting Information). The plots for the inverse of the magnetic susceptibility $\left(1 / \chi_{\mathrm{m}}\right)$ and the $\chi_{\mathrm{m}} \mathrm{T}$ product versus $\mathrm{T}$ at $1 \mathrm{kOe}$ are shown in Figure 3 . The $\chi_{\mathrm{m}} \mathrm{T}$ value at R.T. (6.24 emuKmol $\left.{ }^{-1} \mathrm{Oe}^{-1}\right)$ is lower than expected for a dinuclear species containing non-interacting $\mathrm{Fe}^{3+}(\mathrm{S}=5 / 2)$ ions $\left(8.754 \mathrm{emuKmol}^{-1} \mathrm{Oe}^{-1}\right)$, which suggests the presence of antiferromagnetic exchange interactions at R.T. across the oxalate bridges. ${ }^{[26]}$ This value decreased to $0.54 \mathrm{emuKmol}^{-1} \mathrm{Oe}^{-1}$ at $2 \mathrm{~K}$ and reaches an inflexion point at $c a .20 \mathrm{~K}$. The inverse of the magnetic susceptibility data can be fitted to a Curie-Weiss law (red line in figure 3 ) with paramagnetic Curie temperatures $\left(\theta_{\mathrm{p}}\right)$ close to $44 \mathrm{~K}$ and an effective paramagnetic moment $\mu_{\text {eff }}=10.68 \mu_{\mathrm{B}} /$ molecule. The latter is consistent with the value expected for two $\mathrm{Fe}^{3+}$ ions with high spin $\mathrm{d}^{5}$ configuration $\left(\mu_{\mathrm{eff}}=5.92 \mu_{\mathrm{B}} / \mathrm{Fe}\right.$ ion $)$ and is in a good agreement with that found for other $\mathrm{Fe}(\mathrm{III})$-based halometallate ions. ${ }^{[27,28]}$ In addition, the negative $\theta_{\mathrm{p}}$ value and the reduction of the effective magnetic moment $\left(\chi_{\mathrm{m}} \mathrm{T}\right)$ with the decrease of temperature (see upper inset figure 3) clearly suggest an antiferromagnetic behavior when cooling the sample. On the other hand, the magnetization curve with temperature (measured under an applied field of $0.05 \mathrm{kOe}$ by zero-field-cooled (ZFC) and field-cooled (FC) protocols; see inset of figure 3) displays a splitting 
temperature between both curves at $T_{i r r}=14 \mathrm{~K}$. This behaviour could be attributed to a 3D spin canting structure and is similar to that observed for analogous oxalate bridged iron(III) complexes of formulas $\left\{\left(\mathrm{Me}_{2} \mathrm{NH}_{2}\right)_{2}\left[\mathrm{Fe}_{2} \mathrm{Cl}_{4}(\mu\right.\right.$-ox $\left.\left.)\right] \cdot \mathrm{H}_{2} \mathrm{O}\right\} \mathrm{n}^{[29]}$ and $\left\{\left(\mathrm{MeNH}_{3}\right)_{2}\left[\mathrm{Fe}_{2} \mathrm{Cl}_{4}(\mu-\mathrm{ox})\right] \cdot 2.5 \mathrm{H}_{2} \mathrm{O}\right\}$ n. ${ }^{[30]}$ On the basis of these studies, we conclude that $\left\{(\operatorname{dimim})_{2}\left[\mathrm{Fe}_{2} \mathrm{Cl}_{4}(\mu-\mathrm{ox})\right] \cdot \mathrm{H}_{2} \mathrm{O}\right\}$ n is the most likely structure for $\mathbf{3}$.

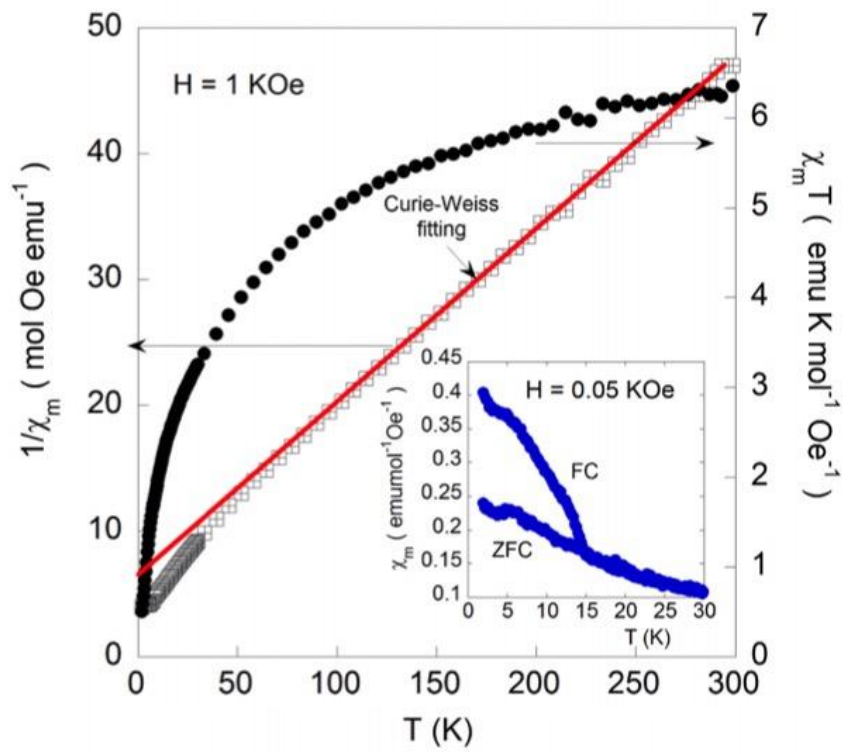

Figure 3. Temperature dependence of $1 / \chi_{\mathrm{m}}$ and $\chi_{\mathrm{mT}}$ measured under $1 \mathrm{kOe}$ in field-cooled-warming (FCW) protocols within the Curie-Weiss fitting. The inset shows the magnetization curve with temperature measured under an applied field of $0.05 \mathrm{kOe}$ by zero-field-cooled (ZFC) and field-cooledcooling (FCC) protocols.

Finally, and as a novelty with respect to our previous study, ${ }^{[13]}$ a series of dielectric spectroscopy studies at $2470 \mathrm{MHz}$ with different temperatures were undertaken in order to evaluate the heating propensity of 3 under microwave irradiation compared to that of the metallic precursor $\mathrm{FeCl}_{3}$. The dielectric characterization was carried out employing the cavity perturbation technique. ${ }^{[31]}$ The dependence of both $\varepsilon^{\prime}$ and $\varepsilon$ ' with temperature are presented in Figure 4. The dielectric properties of $\mathrm{FeCl}_{3}$ do not display any significant variation with temperature and remain fairly stable throughout the measurement process. Such behavior is typical of a salt below its melting point. ${ }^{[31 \mathrm{~d}]}$ On the other hand, both $\varepsilon^{\prime}$ and $\varepsilon$ '” of $\mathbf{3}$ exhibit a substantial increase with temperature above its melting point, demonstrating a thermally activated conductivity mechanism, typical for an IL. ${ }^{[32]}$ These results suggest that the imidazoliumbased oxalate-bridged binuclear iron(III) IL will show superior heating behavior under an electromagnetic field at $2450 \mathrm{MHz}$, with a heating rate substantially higher than that exhibited by $\mathrm{FeCl}_{3}$ once the temperature of the reaction reaches $c a .80{ }^{\circ} \mathrm{C}$. This observation implies a potentially good catalytic performance of $\mathbf{3}$ during a microwave-assisted glycolysis process. 

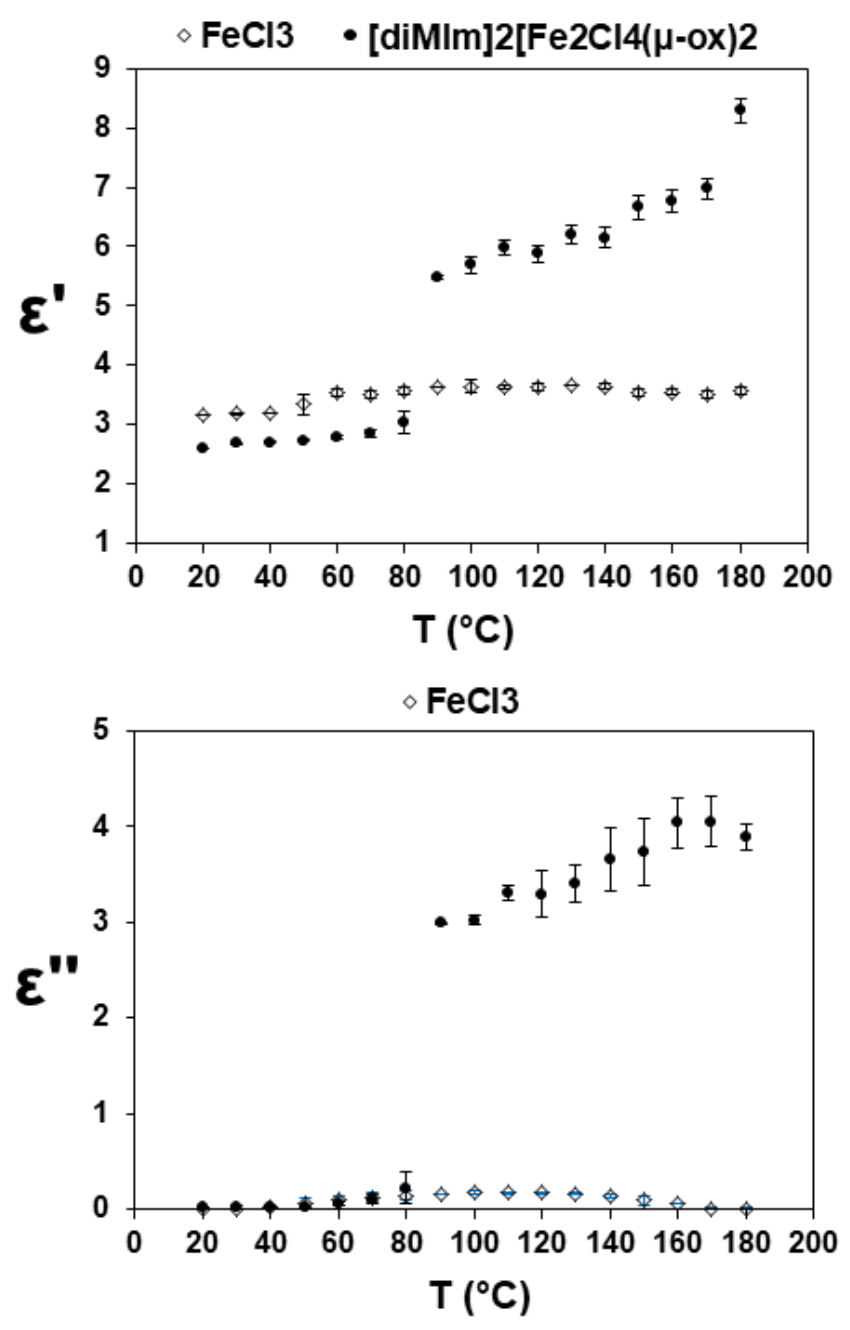

Figure 4. $\varepsilon^{\prime}$ and $\varepsilon^{\prime \prime}$ with temperature at $2470 \mathrm{MHz}$ for 3 and $\mathrm{FeCl}_{3}$.

\section{Catalytic glycolysis of PET with (dimim) $)_{2}\left[\mathrm{Fe}_{2} \mathrm{Cl}_{4}(\mu-0 \mathrm{x})\right](3)$}

The catalytic activity of $\mathbf{3}$ was studied in the depolymerisation of PET to BHET by glycolysis under conventional heating in ethylene glycol (EG). Two sources of PET were employed: pellets (Goodfellow Inc. (3-5 mm)) (PET-1) and used PET sourced from water bottles obtained from a local market and cut to an approximate size of $6 \mathrm{~mm}$ (PET-2). Firstly, in this work we have performed a thorough analysis of the optimal reaction conditions. Table 1 displays the influence of catalyst loading in the glycolysis of PET at $170{ }^{\circ} \mathrm{C}$ and $24 \mathrm{~h}$ as reaction time. The mass of consumed PET and conversion to BHET product increase as the catalyst loading is higher, reaching $96 \%$ and $60 \%$ respectively with $0.082 \mathrm{mmol}$ of 3 . 
Table 1. Influence of catalyst loading in the glycolysis reaction catalysed by $3{ }^{\left[{ }^{[a]}\right.}$

\begin{tabular}{|c|c|c|c|c|}
\hline Entry & [cat] (mol) & Mass of consumed PET $(\%)$ & BHET selectivity $(\%)^{[\mathrm{b}]}$ & BHET conversion $(\%)^{[\mathrm{b}]}$ \\
\hline 1 & 0.011 & 34 & 43 & 14 \\
\hline 2 & 0.022 & 30 & 56 & 17 \\
\hline 3 & 0.045 & 73 & 40 & 29 \\
\hline 4 & 0.090 & 96 & 60 & 60 \\
\hline
\end{tabular}

${ }^{[a]}$ Reagents and conditions: $170{ }^{\circ} \mathrm{C}, 24 \mathrm{~h}$, PET-1 $(250 \mathrm{mg})$, EG $(1.5 \mathrm{~mL}) .{ }^{\left[{ }^{[b]}\right.}$ BHET amount determined by ${ }^{1} \mathrm{H}$ NMR spectroscopy as the average of two runs, employing 1-phenyl-1,2-ethanediol as internal standard. ${ }^{[33]}$

Mass of consumed PET and conversion to BHET product increase with the reaction time, but with a slight decrease in selectivity towards BHET (Figure 5). This is attributable to the existing equilibrium between monomers and oligomers, which leads to the repolymerization of BHET product generated in the glycolysis process as the time progresses. ${ }^{[12 c, f]}$

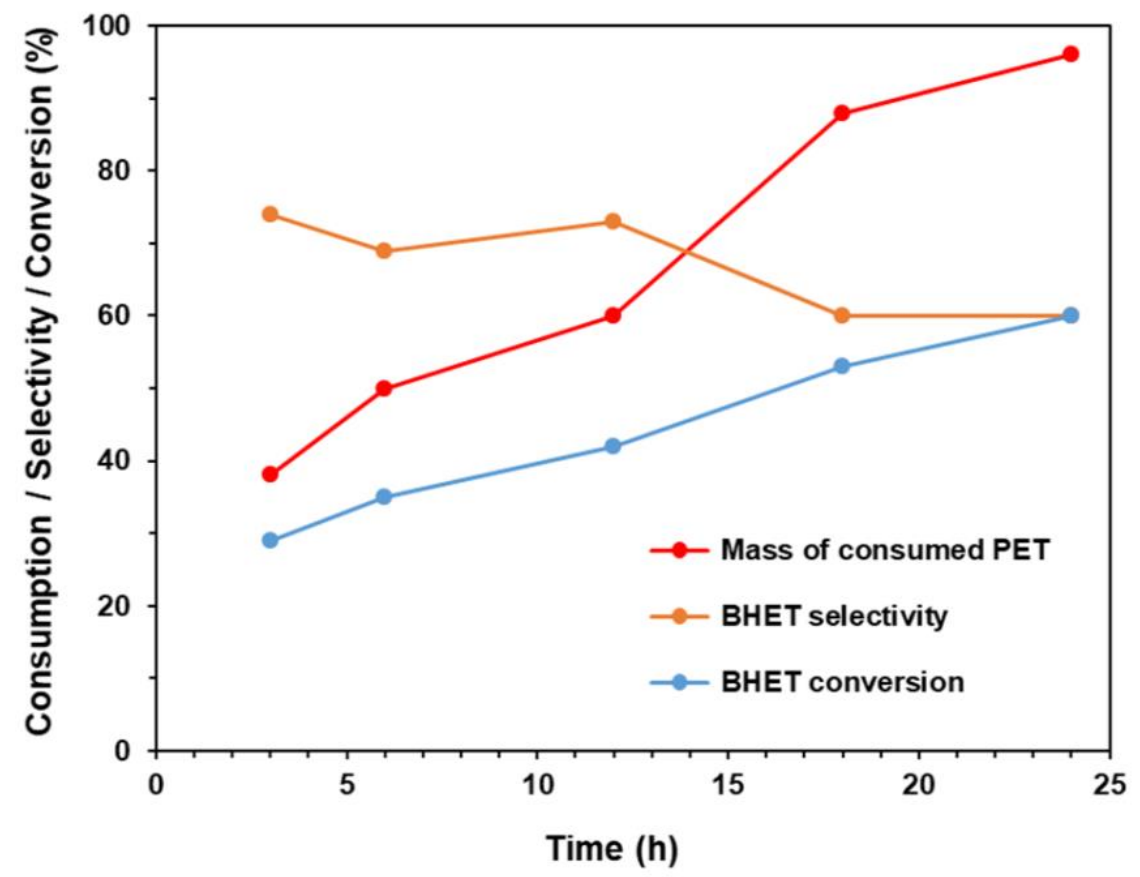

Figure 5. Influence of time in the glycolysis of PET catalyzed by 3. Reagents and conditions: PET-1 (250 mg), 3 (0.09 mmol), EG (1.5 mL), $170{ }^{\circ} \mathrm{C}$.

Finally, we studied the influence of temperature on the catalytic reaction (Table 2). As expected, the degradation of PET is favoured by an increase in the reaction temperature (entries 1-4), since the higher the temperature is, the higher the mass of consumed PET and conversion to BHET product, obtaining $96 \%$ consumption and $60 \%$ conversion to BHET at $170{ }^{\circ} \mathrm{C}$ (entry 4). In contrast, the selectivity of BHET 
product reached a maximum of $94 \%$ at $150{ }^{\circ} \mathrm{C}$ but then decays with the rise of temperature due to the re-polymerisation of BHET monomer into dimers and oligomers. Therefore, the optimal reaction conditions found under conventional heating are $1.5 \mathrm{~mL}$ of EG, $170{ }^{\circ} \mathrm{C}$ and $24 \mathrm{~h}$ of reaction time, resulting in a $60 \%$ conversion. Interestingly, the glycolysis of PET-2 (waste bottles) instead of PET-1 (pellets) was performed with complete consumption of all initial PET, which was transformed into BHET, dimers and oligomers (Table 2, entry 5). Higher selectivity and conversion towards BHET product was obtained. This can be explained by the higher surface area from PET-2.

Table 2. Influence of temperature for the PET glycolysis catalysed by $\mathbf{3}^{[\mathrm{a}]}$

\begin{tabular}{cccccc}
\hline Entry & PET & T $\left({ }^{\circ} \mathrm{C}\right)$ & $\begin{array}{c}\text { Mass of consumed } \\
\text { PET }(\%)\end{array}$ & $\begin{array}{c}\text { BHET selectivity } \\
(\%)^{[\mathrm{b}]}\end{array}$ & $\begin{array}{c}\text { BHET conversion } \\
(\%)^{[\mathrm{b}]}\end{array}$ \\
\hline 1 & PET-1 & 140 & 23 & 85 & 20 \\
2 & PET-1 & 150 & 24 & 94 & 23 \\
3 & PET-1 & 160 & 45 & 78 & 34 \\
$\mathbf{4}$ & PET-1 & $\mathbf{1 7 0}$ & $\mathbf{9 6}$ & $\mathbf{6 0}$ & $\mathbf{6 0}$ \\
$\mathbf{5}$ & PET-2 & $\mathbf{1 7 0}$ & $>99$ & $\mathbf{8 0}$ & $\mathbf{8 0}$
\end{tabular}

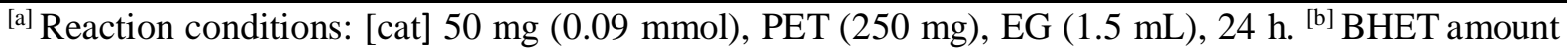
determined by ${ }^{1} \mathrm{H}$ NMR spectroscopy as the average of two runs, employing 1-phenyl-1,2-ethanediol as internal standard.

In addition, several control experiments were performed under thermal heating to determine the implication of $\mathbf{3}$ in the catalytic reaction (Table 3). Firstly, no reaction was observed without metalcontaining IL (entry 1) or when glycerol was employed instead of EG (entry 2), indicating that both catalyst and EG are involved in the process. In addition, the catalytic activity of (dimim) $\mathrm{Cl}$ and the metal precursor $\mathrm{FeCl}_{3}$ were lower than that of the $\mathrm{Fe}$-based ionic liquid under the optimized reaction conditions (entries 3 and 4). These experiments reveal that both the cation $\left((\operatorname{dimim})^{+}\right)$and the anion $\left(\left[\mathrm{Fe}_{2} \mathrm{Cl}_{4}(\mu-\mathrm{ox})\right]^{2-}\right)$ play an important role in the degradation of PET, and demonstrates a synergistic effect of the two fragments. 
Table 3. Control experiments for the glycolysis of PET. ${ }^{[a]}$

\begin{tabular}{ccccc}
\hline Entry & Catalyst & Mass of consumed PET $(\%)$ & BHET selectivity $(\%)^{[\mathrm{b}]}$ & BHET conversion $(\%)^{[\mathrm{b}]}$ \\
\hline 1 & -- & 0 & 0 & 0 \\
$2^{[\mathrm{c}]}$ & $\mathbf{3}$ & 0 & 0 & 0 \\
$3^{[\mathrm{d}]}$ & $($ dimim $) \mathrm{Cl}$ & 11 & 69 & 7 \\
$4^{[\mathrm{e}]}$ & $\mathrm{FeCl}_{3}$ & 74 & 52 & 38 \\
\hline
\end{tabular}

[a] Reagents and conditions: PET-1 (250 mg), EG $(1.5 \mathrm{~mL}), 170{ }^{\circ} \mathrm{C}, 24 \mathrm{~h} \cdot{ }^{[\mathrm{b}]}$ BHET amount determined by ${ }^{1} \mathrm{H}$ NMR spectroscopy as the average of two runs, employing 1-phenyl-1,2-ethanediol as internal standard. ${ }^{[c]}$ Glycerol employed as solvent, 3 (0.09 mmol). ${ }^{[d]} 0.165 \mathrm{mmol}(\mathrm{dimim}) \mathrm{Cl} .{ }^{\text {[e] }} 0.165 \mathrm{mmol}$ $\mathrm{FeCl}_{3}$.

The dielectric properties of $\mathbf{3}$ prompted us to evaluate its catalytic activity in the depolymerisation of PET using microwave heating and employing some of the optimised reaction conditions applied under conventional heating $(0.082 \mathrm{mmol}$ catalyst, $250 \mathrm{mg}$ PET and $1.5 \mathrm{~mL}$ EG; for further details see Experimental Section). Microwave irradiation penetrates in the material and transfers energy by dielectric vibration to the molecules present in the catalytic reaction system, resulting in a temperature increase. ${ }^{[34]}$ First, we performed a set of experiments with PET pellets at $160{ }^{\circ} \mathrm{C}$ and $170{ }^{\circ} \mathrm{C}$ (Table 4). The system required $5 \mathrm{~W}$ to maintain $160{ }^{\circ} \mathrm{C}$ as reaction temperature, giving $13 \%$ conversion and $70 \%$ selectivity towards BHET in $3 \mathrm{~h}$ (entry 1). An increase in the reaction time up to $6 \mathrm{~h}$ provided an improvement in the results, obtaining the BHET product with higher selectivity and conversion ( 80 and $32 \%$, respectively, entry 2). Interestingly, a significant enhancement of activity was observed at $170{ }^{\circ} \mathrm{C}$ (entries 3-5), reaching $72 \%$ consumption of PET and 52\% conversion to BHET in $3 \mathrm{~h}$ (entry 5), whereas the system only needed $6 \mathrm{~W}$ to maintain the desired temperature. On the contrary, the depolymerisation of PET catalysed by $\mathrm{FeCl}_{3}$ required $10 \mathrm{~W}$, yielding $94 \%$ selectivity and $17 \%$ conversion towards BHET product (entry 6). In good agreement with dielectric spectroscopy studies, the halometallate complex acts as main heating source in such a way that the catalyst absorbs more efficiently the microwave radiation and thus needs less energy than the simple metal salt to maintain the heating at the required temperature.

Subsequently, a set of catalytic experiments were performed at a constant microwave power of $100 \mathrm{~W}$ and $170{ }^{\circ} \mathrm{C}$ as maximum reaction temperature (entries 7-9). The catalytic activity increased with higher irradiation power. In fact, the process required less time ( $2 \mathrm{~h}$, entry 9$)$ to show comparable performance to that obtained at a lower irradiation power of $6 \mathrm{~W}$ (3 h, entry 5). Logically, an increase in the specific surface area resulted in an increase in activity and the use of ground PET led to a 65\% conversion and $68 \%$ selectivity in 30 min, while the consumption of PET was $95 \%$ (entry 8 ). 
Table 4. Optimization Parameters for the Glycolysis of PET pellets catalyzed by $\mathbf{3}$ employing a microwave system. ${ }^{[a]}$

\begin{tabular}{ccccccc}
\hline Entry & Power $(\mathrm{W})$ & $\mathrm{T}\left({ }^{\circ} \mathrm{C}\right)$ & Time $(\mathrm{h})$ & $\begin{array}{c}\text { Mass of consumed } \\
\text { PET }(\%)\end{array}$ & $\begin{array}{c}\text { BHET } \\
\text { selectivity }(\%)^{[\mathrm{b}]}\end{array}$ & $\begin{array}{c}\text { BHET conversion } \\
(\%)^{[\mathrm{b}]}\end{array}$ \\
\hline 1 & 5 & 160 & 3 & 17 & 70 & 13 \\
2 & 5 & 160 & 6 & 39 & 80 & 32 \\
3 & 6 & 170 & 0.5 & 3 & 52 & 2 \\
4 & 6 & 170 & 2 & 54 & 86 & 46 \\
$\mathbf{5}$ & $\mathbf{6}$ & $\mathbf{1 7 0}$ & $\mathbf{3}$ & $\mathbf{7 2}$ & $\mathbf{7 1}$ & $\mathbf{5 2}$ \\
$6^{[\mathrm{cc}]}$ & 10 & 170 & 3 & 18 & 94 & 17 \\
7 & 100 & 170 & 0.5 & 32 & 77 & 25 \\
$\mathbf{8}^{[\mathrm{d}]}$ & $\mathbf{1 0 0}$ & $\mathbf{1 7 0}$ & $\mathbf{0 . 5}$ & $\mathbf{9 5}$ & $\mathbf{6 8}$ & $\mathbf{6 5}$ \\
$\mathbf{9}$ & $\mathbf{1 0 0}$ & $\mathbf{1 7 0}$ & $\mathbf{2}$ & $\mathbf{7 4}$ & $\mathbf{7 4}$ & $\mathbf{5 6}$ \\
\hline
\end{tabular}

[a] Reagents and conditions: PET-1 $(250 \mathrm{mg})$, [cat]: $50 \mathrm{mg}(0.09 \mathrm{mmol})$, EG $(1.5 \mathrm{~mL}) .{ }^{[\mathrm{b}]}$ BHET amount determined by ${ }^{1} \mathrm{H}$ NMR spectroscopy as the average of two runs, employing 1-phenyl-1,2-ethanediol as internal standard. ${ }^{[\mathrm{c}]} 0.18 \mathrm{mmol} \mathrm{FeCl}_{3} .{ }^{[\mathrm{d}]}$ Ground PET-1.

Commercial PET cut from bottles (PET-2) showed a higher mass consumption of PET and conversion and selectivity towards BHET (Table 5). The glycolysis of PET at $160{ }^{\circ} \mathrm{C}$ proceeded with $96 \%$ consumption in $3 \mathrm{~h}$ (entry 1), while the conversion and selectivity were 54\% and 56\%, respectively. Quantitative consumption of PET and slightly higher conversion and selectivity towards BHET product were observed when increasing the reaction time up to $6 \mathrm{~h}$ (entry 2). Most importantly, we noted a significant increase in the activity at $170^{\circ} \mathrm{C}$ (entries 3-5), providing quantitative formation of BHET in $3 \mathrm{~h}$ (entry 7). Good results were also obtained fixing the microwave power at $100 \mathrm{~W}$ and the temperature at $170^{\circ} \mathrm{C}$ (entries 6 and 7). Indeed, nearly quantitative consumption of PET was reached in $30 \mathrm{~min}$, whereas the conversion and selectivity to BHET were higher than $70 \%$. The catalyst reported herein displays better catalytic performance under microwave heating than those shown by iron-containing ILs described in our previous work. ${ }^{[13]}$ The importance of microwave methodology in terms of efficiency and reduction in reaction time is evidenced by the comparison with the use of thermal heating, where quantitative consumption of PET was observed after $24 \mathrm{~h}$ of reaction time. 
Table 5. Optimization of the reaction parameters for PET-2 employing a microwave system. ${ }^{\text {a] }}$

\begin{tabular}{ccccccc}
\hline Entry & Power $(\mathrm{W})$ & $\mathrm{T}\left({ }^{\circ} \mathrm{C}\right)$ & Time $(\mathrm{h})$ & $\begin{array}{c}\text { Mass of consumed } \\
\text { PET }(\%)\end{array}$ & $\begin{array}{c}\text { BHET } \\
\left.\text { selectivity }(\%)^{[\mathrm{b}]}\right]\end{array}$ & $\begin{array}{c}\text { BHET } \\
\text { conversion }(\%)^{[\mathrm{b}]}\end{array}$ \\
\hline 1 & 5 & 160 & 3 & 96 & 56 & 54 \\
2 & 5 & 160 & 6 & $>99$ & 58 & 58 \\
3 & 6 & 170 & 0.5 & 39 & $>99$ & 39 \\
4 & 6 & 170 & 2 & 92 & 54 & 50 \\
$\mathbf{5}$ & $\mathbf{6}$ & $\mathbf{1 7 0}$ & $\mathbf{3}$ & $>99$ & $>99$ & $>99$ \\
6 & 100 & 170 & 0.5 & 96 & 73 & 71 \\
7 & 100 & 170 & 2 & $>99$ & 77 & 77 \\
\hline
\end{tabular}

[a] Reagents and conditions: PET-2 (250 mg), [cat]: $50 \mathrm{mg}(0.09 \mathrm{mmol})$, EG $(1.5 \mathrm{~mL}){ }^{\text {[b] }}$ BHET amount determined by ${ }^{1} \mathrm{H}$ NMR spectroscopy as the average of two runs, employing 1-phenyl-1,2-ethanediol as internal standard.

In addition, gram-scale reactions with $2.5 \mathrm{~g}$ of discarded commercial PET bottles (PET-2) were demonstrated under both thermal and microwave heating conditions (Table 6). Through conventional heating, complete consumption of PET, and 78\% conversion and selectivity towards BHET were observed (entry 1). The use of microwave methodology also provided quantitative consumption of PET, and $89 \%$ yield and selectivity towards BHET (entry 2). These experiments prove the potential application of the described catalytic system for large-scale glycolysis of PET.

Table 6. Influence of catalyst loading in the glycolysis of PET catalyzed by $3 .^{[a]}$

\begin{tabular}{cccccc}
\hline Entry & Heating & Time (h) & $\begin{array}{c}\text { Mass of consumed } \\
\text { PET }(\%)\end{array}$ & $\begin{array}{c}\text { BHET selectivity } \\
(\%)^{[\mathrm{b}]}\end{array}$ & $\begin{array}{c}\text { BHET conversion } \\
(\%)^{[\mathrm{b}]}\end{array}$ \\
\hline 1 & conventional & 24 & $>99$ & 78 & 78 \\
$2^{[\mathrm{cc}]}$ & microwave & 3 & $>99$ & 89 & 89 \\
\hline
\end{tabular}

${ }^{[a]}$ Reagents and conditions: PET-2 $(2.5 \mathrm{~g}), 3(0.9 \mathrm{mmol})$, EG $(15 \mathrm{~mL}), 170{ }^{\circ} \mathrm{C}$. ${ }^{[b]}$ BHET amount determined by ${ }^{1} \mathrm{H}$ NMR spectroscopy as the average of two runs, employing 1-phenyl-1,2-ethanediol as internal standard. ${ }^{[\mathrm{cc}} 6 \mathrm{~W}$ (standard control).

Finally, the catalyst exhibited a limited potential for recyclability. We carried out several experiments to investigate the recyclability of $\mathbf{3}$. The binuclear iron complex could be recovered and used in successive cycles by precipitation in water. However, a significant decrease in the activity was observed in the second cycle (Figure S4, Supporting Information). We have characterized the iron-containing IL after the catalytic reaction by IR and TGA. No stretching bands corresponding to oxalate were found in the IR spectrum of the recovered catalyst, which shows that the binuclear iron complex is decomposed 
(Figure S5). There is also a shift in the $\mathrm{N}-\mathrm{CH}_{3}$ band of the imidazolium moiety. This is supported by TGA, since the mass of the final residue is higher than that found in the TGA of the non-used catalyst (Figure S6). In addition, the TGA curve exhibits several weight loss due to new decomposition temperatures. Consequently, these analyses suggest that the iron catalyst has decomposed during the purification process.

\section{Characterization of BHET Product}

The BHET product was isolated by crystallization in water at $4{ }^{\circ} \mathrm{C}$ (see Experimental Section for more details) and characterized by DSC, ATR FT-IR, TGA, NMR, electrospray ionization mass spectrometry (ESI-MS), powder X-Ray diffraction (PXRD), and gas chromatography mass spectrometry (GC-MS). PXRD data (Figure S7, Supporting Information) confirmed unit cell parameters in agreement with literature reports (Table S2, Supporting Information), ${ }^{[35]}$ with no unmatched diffraction peaks. The polymer (Inset of figure S7) shows the characteristic diffraction pattern of PET with a semicrystalline structure. ${ }^{[36]}{ }^{1} \mathrm{H}$ and ${ }^{13} \mathrm{C}$ NMR spectra confirmed the purity of the product (Figure S8 and S9, Supporting Information) ${ }^{[37]}$

A melting point of $109.7^{\circ} \mathrm{C}$ was confirmed by DSC, which is in good agreement with that published for BHET (Figure S10, Supporting Information) ${ }^{[34,38]}$ Similarly, TGA gave a weight loss of $c a .27 \%$ at $210^{\circ} \mathrm{C}$, due to the thermal decomposition of BHET product, and another weight loss of about $61 \%$ at $422^{\circ} \mathrm{C}$ corresponding to the thermal decomposition of PET repolymerized during the heating performed in the TGA analysis (Figure S11, Supporting Information). ${ }^{[12 c, 37,39]}$ In addition, FT-IR spectrum is consistent with literature reports (Figure S12, Supporting Information). ${ }^{[37]}$ Finally, the purity of the BHET synthesized was further confirmed by GC-MS and ESI-MS (Figures S13 and S14, Supporting Information), which demonstrated that highly pure BHET product was obtained. Indeed, no signals attributable to other compounds were detected.

\section{CONCLUSION}

In summary, a new oxalate-bridged binuclear iron(III) ionic liquid based on imidazolium cation, (dimim) $)_{2}\left[\mathrm{Fe}_{2} \mathrm{Cl}_{4}(\mu\right.$-ox $\left.)\right]$, has been synthesized, fully characterized and successfully employed as catalyst for the glycolysis of PET, under thermal and microwave-assisted heating conditions. Such an oxalate complex was selected for its dielectric properties, which involve a higher heating rate under an electromagnetic field compared to that of $\mathrm{FeCl}_{3}$ and thus a potentially better catalytic performance during a microwave-assisted glycolysis process. Quantitative consumption of PET and high conversions to BHET were obtained through the two approaches, but much shorter reaction times and energy consumption were observed when microwave-assisted heating conditions were employed. Indeed, the complex provided higher conversion to BHET product through microwave conditions in remarkably 
less time than that required under conventional heating (>99\% in $3 \mathrm{~h}$ vs $80 \%$ in $24 \mathrm{~h}$ for post-consumer PET).

In conclusion, we have devised a novel oxalate-bridged halometallate ILs with very exciting dielectric properties, which has evidenced its suitability as an active catalyst for degradation of PET, in particular under microwave heating conditions.

\section{EXPERIMENTAL SECTION}

\section{General}

Reagents were purchased from Sigma Aldrich and purified when required following literature protocols. ${ }^{[40]}$ Chemical shifts of ${ }^{1} \mathrm{H}$ and ${ }^{13} \mathrm{C}$ NMR are reported in ppm, employing the solvent as internal standard. Signals are quoted as s (singlet), t (triplet).

\section{Synthesis of imidazolium-based oxalate-bridged binuclear iron(III) ionic líquid (3)}

$700 \mathrm{~mL}$ of an aqueous solution of sodium hydroxide $(1 \mathrm{M})$ were passed through a column filled with an ion exchange resin (Amberlite IRA, basic form, $75 \mathrm{~g}$ ). Next, the column was washed with distilled water until the $\mathrm{pH}$ of the effluent was neutral. Afterwards, 1,3-dimethylimidazolium iodide (13.13 mmol, $2.942 \mathrm{~g}$ ) was dissolved in water and eluted through the column to yield 1,3-dimethylimidazolium hydroxide (dimim) OH (1). Oxalic acid $(6.57 \mathrm{mmol}, 0.827 \mathrm{~g})$ was then added to the aqueous solution of 1 to form of the oxalic-based IL (dimim) ${ }_{2} \mathrm{Ox}(2)$. This solution was added dropwise to a well-stirred 50 $\mathrm{mL}$ aqueous solution of $\mathrm{FeCl}_{3}(13.13 \mathrm{mmol}, 2.13 \mathrm{~g})$ at room temperature (R.T.) to yield (dimim) $)_{2}\left[\mathrm{Fe}_{2} \mathrm{Cl}_{4}(\mu\right.$-ox) $](3)$. After solvent removal under vacuum at $40{ }^{\circ} \mathrm{C}$, a yellow powder $(3)$ was obtained, which was washed with methanol $(\mathrm{MeOH})$. Yield: $2.876 \mathrm{~g}, 81 \%$. Elemental analysis: calculated for $\mathrm{C}_{12} \mathrm{H}_{20} \mathrm{Cl}_{4} \mathrm{Fe}_{2} \mathrm{~N}_{4} \mathrm{O}_{4} \cdot \mathrm{H}_{2} \mathrm{O}$. C, 25.93; H, 3.99; N, 10.08. Found. C, 26.56; H, 3.07; N, 9.25. ICP-OES (\% weight): Calculated Fe, 20.09; found. Fe, 20.18. TGA: 80.6\% mass loss.

\section{Catalytic depolymerisation of PET}

General procedure for thermal heating: Protocol adapted from reference 13. Typically, $250 \mathrm{mg}$ of PET (commercial pellets or PET waste), $1.5 \mathrm{~mL}$ of EG and the corresponding amount of catalyst were placed in a $10 \mathrm{~mL}$ round bottom flask. The mixture was heated under reflux to the selected temperature and maintained during the reaction time, and afterwards the solution was allowed to cool down to R.T. Then, the reaction mixture was combined with $100 \mathrm{~mL}$ of distilled water. The unreacted polymer was separated and dried at $80^{\circ} \mathrm{C}$, and the mixture was filtered out. The water was evaporated under vacuum (72 mbar) at $40{ }^{\circ} \mathrm{C} .100 \mathrm{mg}$ of the remaining solution was dissolved in DMSO-d6 and analyzed by ${ }^{1} \mathrm{H}$ and ${ }^{13} \mathrm{C}$ NMR using 1-phenyl-1,2-ethanediol $(0.1 \mathrm{mmol})$ as internal standard. BHET was crystallized at $4{ }^{\circ} \mathrm{C}$ by addition of $7 \mathrm{~mL}$ of distilled water to the residue.

General procedure for microwave-assisted heating: Protocol adapted from reference 13 . These experiments were performed in a CEM microwave reactor. Typically, $250 \mathrm{mg}$ of PET (pellets or waste PET) $1.5 \mathrm{~mL}$ of EG and the corresponding amount of catalyst were placed in 
a special reaction vial. The vial was inserted in the microwave reactor. Then, the microwave was programmed to maintain a constant temperature with either fixed or automatically controlled heating power. After the reaction was finished, the vial was allowed to cool to R.T. and a similar procedure to that previously described was employed.

The consumption of PET is calculated as follows:

$$
\text { Mass of consumed PET }(\%)=\frac{W_{0}-W_{1}}{W_{0}} \times 100
$$

where $W_{0}$ corresponds to the initial weight of PET and $W_{1}$ corresponds to the weight of unreacted PET. In addition, the conversion and selectivity towards BHET product are defined by equations (3) and (4):

$$
\begin{gathered}
\text { BHET conversion }=\frac{\text { moles of BHET }}{\text { initial moles of PET units }} \times 100 \\
\text { BHET selectivity }=\frac{\text { moles of BHET }}{\text { moles of depolymerized PET units }} \times 100
\end{gathered}
$$

\section{AUTHOR INFORMATION}

\section{Corresponding Authors}

*E-mail: Victor.SansSangorrin@ nottingham.ac.uk (Victor Sans)

*E-mail: depedrovm@unican.es (Imanol de Pedro)

*E-mail: israel.canorico@nottingham.ac.uk (Israel Cano)

\section{ORCID}

Victor Sans: 0000-0001-7045-5244

Imanol de Pedro: 0000-0002-5581-2220

Israel Cano: 0000-0003-3727-9327

\section{CONFLICTS OF INTEREST}

There are no conflicts of interest to declare.

\section{ACKNOWLEDGMENTS}

The Universidad de Cantabria (Proyecto Puente convocatoria 2018 financed by SODERCAN_FEDER) is acknowledged for funding. Israel Cano thanks financial support from the Marie Skłodowska-Curie Individual Fellowship (IF-EF; Pro: 704710-Sdchirnanocat). The EPSRC Centre for Doctoral Training in Sustainable Chemistry (EP/L015633/1) is gratefully acknowledged for the support to M. K. Leu. Victor Sans gratefully acknowledges the Generalitat Valenciana (GVA) CIDEGENT program for funding. 


\section{REFERENCES}

[1] U. T. Bornscheuer, Science 2016, 351, 1154-1155.

[2] L. Bartolome, M. Imran, B. G. Cho, W. A. Al-Masry, D. H. Kim in Recent Developments in the Chemical Recycling of PET, Material Recycling - Trends and Perspectives (Ed.: D. Achilias), InTech, Rijeka, 2012, pp. 65-84.

[3] A. Lusher, P. Hollman, J. Mendoza-Hill, Microplastics in fisheries and aquaculture: status of knowledge on their occurrence and implications for aquatic organisms and food safety, FAO Fisheries and Aquaculture Technical Paper, 2017, 615.

[4] A. M. Al-Sabagh, F. Z. Yehia, Gh. Eshaq, A. M. Rabie, A. E. ElMetwally, Egypt. J. Pet. 2016, 25, $53-64$.

[5] N. George, T. Kurian, Ind. Eng. Chem. Res. 2014, 53, 14185-14198.

[6] Q. Wang, X. Yao, S. Tang, X. Lu, X. Zhang, S. Zhang, Green Chem. 2012, 14, 2559-2566.

[7] B. Geyer, G. Lorenz, A. Kandelbauer, eXPRESS Polym. Lett. 2016, 10, 559-586.

[8] a) M. A. Alnaqbi, M. A. Mohsin, R. M. Busheer, Y. Haik, J. Appl. Polym. Sci. 2015, 132, 41666;

b) C. Jehanno, I. Flores, A. P. Dove, A. J. Müller, F. Ruipérez, H. Sardon, Green Chem. 2018, 20, $1205-$ 1212.

[9] Q. Wang, X. Yao, Y. Geng, Q. Zhou, X. Lu, S. Zhang, Green Chem. 2015, 17, 2473-2479.

[10] J. P. Hallett, T. Welton, Chem. Rev. 2011, 111, 3508-3576.

[11] V. Gonçalves-Maciel, D. J. Wales, M. Seferin, C. M. L. Ugaya, V. Sans, J. Clean. Prod., 2019, $217,844-858$

[12] a) H. Wang, Z. Li, Y. Liu, X. Zhang, S. Zhang, Green Chem. 2009, 11, 1568-1575; b) H. Wang, R. Yan, Z. Li, X. Zhang, S. Zhang, Catal. Commun. 2010, 11, 763-767; c) X. Zhou, X. Lu, Q. Wang, M. Zhu, Z. Li, Pure Appl. Chem. 2012, 84, 789-801; d) Q. Wang, X. Lu, X. Zhou, M. Zhu, H. He, X. Zhang, J. Appl. Polym. Sci. 2013, 129, 3574-3581; e) Q. F. Yue, L. F. Xiao, M. L. Zhang, X. F. Bai, Polymers 2013, 5, 1258-1271; f) Q. Wang, Y. Geng, X. Lu, S. Zhang, ACS. Sustain. Chem. Eng. 2015, 3, 340-348.

[13] F. Scé, I. Cano, C. Martin, G. Beobide, Ó. Castillo, I. de Pedro, New. J. Chem. 2019, 43, 34763485 .

[14] a) G. M. Gadd, Microbiology 2010, 156, 609-643; b) R. L. Frost, Anal. Chim. Acta 2004, 517, 207-214.

[15] a) E. Coronado, P. Day, Chem. Rev. 2004, 104, 5419-5448 and references therein; b) F. Abraham, B. Arab-Chapelet, M. Rivenet, C. Tamain, S. Grandjean, Coord. Chem. Rev. 2014, 266, 28-68.

[16] a) Functional hybrid materials (Eds.: P. Gómez-Romero, C. Sanchez), John Wiley \& Sons, 2006; b) A. Dikhtiarenko, S. A. Khainakov, I. de Pedro, J. A. Blanco, J. R. García, J. Gimeno, Inorg. Chem. 
2013, 52, 3933-3941; c) B. A. DeGraff, G. D. Cooper, J. Phys. Chem. 1971, 75, 2897-2902; d) J. Lu, Y. Li, K. Zhao, J. Q. Xu, J. H. Yu, G. H. Li, T. G. Wang, Inorg. Chem. Commun. 2004, 7, 1154-1156; e) D. Armentano, G. De Munno, F. Lloret, A. V. Palii, M. Julve, Inorg. Chem. 2002, 41, 2007-2013; f)

E. Coronado, J. R. Galan-Mascaros, C. J. Gomez-Garcia and V. Laukhin, Nature, 2000, 408, 447-449;

g) O. Castillo, A. Luque, P. Roman, F. Lloret, M. Julve, Inorg. Chem. 2001, 40, 5526-5535.

[17] G. Dimitrakis, I. J. Villar-Garcia, E. Lester, P. Licence, S. Kingman, Phys. Chem. Chem. Phys. 2008, 10, 2947-2951.

[18] A.C. Metaxas, R. J. Meredith in Industrial Microwave Heating, IEE Power Engineering Series 4, (Eds.: A. T. Johns, G. Ratcliff, J. R. Platts)London, 1983.

[19] E. R. Talaty, S. Raja, V. J. Storhaug, A. Dölle, W. R. Carper, J. Phys. Chem. B 2004, 108, $13177-$ 13184.

[20] R. Kore, P. Berton, S. P. Kelley, P. Aduri, S. S. Katti, R. D. Rogers, ACS Catal. 2017, 7, 7014 7028.

[21] K. M. Begun, W. H. Fletcher, Spectrochim. Acta 1963, 19, 1343-1349.

[22] M. C. D'Antonio, A. Wladimirsky, D. Palacios, L. Coggiolaa, A. C. González-Baró, E. J. Baran, R. C. Mercader, J. Braz. Chem. Soc. 2009, 20, 445-450.

[23] A. García-Saiz, P. Migowski, O. Vallcorba, J. Junquera, J. A. Blanco, J. A. González, I. De Pedro, Chem. Eur. J. 2014, 20, 72-76.

[24] A. García-Saiz, I. de Pedro, P. Migowski, O. Vallcorba, J. Junquera, J. A. Blanco, J. Rius, Inorg. Chem. 2014, 53, 8384-8396.

[25] N. Mancilla, V. Caliva, M. C. D'Antonio, A. C. González-Baró, E. J. Baran, J. Raman Spectrosc. 2009, 40, 915-920.

[26] M. Clemente-León, E. Coronado, C. Martí-Gastaldo, F. M. Romero, Chem. Soc. Rev. 2011, 40, 473-497.

[27] A. García-Saiz, I. de Pedro, O. Vallcorba, P. Migowski, I. Hernández, L. F. Barquín, I. Abrahams, M. Motevalli, J. Dupont, J. A. González, J. Rodríguez-Fernández, RSC Adv. 2015, 5, 60835-60848.

[28] I. de Pedro, O. Fabelo, A. García-Saiz, O. Vallcorba, J. Junquera, J. A. Blanco, J. C. Waerenborgh, D. Andreica, A. Wildes, M. T. Fernández-Díaz, J. Rodríguez-Fernández, Phys. Chem. Chem. Phys. 2016, 18, 21881-21892.

[29] D. Armentano, T. F. Mastropietro, G. De Munno, P. Rossi, F. Lloret, M. Julve, Inorg. Chem. 2008, 47, 3772-3786.

[30] T. F. Mastropietro, N. Marino, G. D. Munno, F. Lloret, M. Julve, E. Pardo, D. Armentano, Inorg. Chem. 2016, 55, 11160-11169.

[31] a) A. D. Smith, E. H. Lester, K. J. Thurecht, S. W. Kingman, J. E. Harfi, G. Dimitrakis, J. P. Robinson, D. J. Irvine, Ind. Eng. Chem. Res. 2010, 49, 3011-3014; b) A. Navarrete, R. B. Mato, G. Dimitrakis, E. Lester, J. R. Robinson, M. J. Cocerq,8. Kingman, Ind. Crops Prod. 2011, 33, 697-703; 
c) J. G. P. Binner, G. Dimitrakis, D. M. Price, M. Reading, B. Vaidhyanathan, J. Therm. Anal. Calorim. 2006, 84, 409-412; d) K. Wang, G. Dimitrakis, D. J. Irvine, Chem. Eng. Process. 2017, 122, 389-396. [32] J. Robinson, S. Kingman, D. Irvine, P. Licence, A. Smith, G. Dimitrakis, D. Obermayer, C. O. Kappe, Phys. Chem. Chem. Phys. 2010, 12, 4750-4758.

[33] In general, the deviation from the average value was $\pm 5 \%$ for mass of consumed PET, $\pm 5 \%$ for conversion to BHET, and $\pm 7 \%$ for selectivity towards BHET.

[34] N. Pingale, S. Shukla, Eur. Polym. J. 2008, 44, 4151-4156.

[35] S. Kashino, M. Haisa, Acta Cryst. 1975, B31, 1819-1822.

[36] S. D. Gates, T. N. Blanton, T. G. Fawcett, Powder Diffrac. 2014, 29, 102-107.

[37] D. S. Achilias, H. H. Redhwi, M. N. Siddiqui, A. K. Nikolaidis, D. N. Bikiaris, G. P. Karayannidis, J. Appl. Polym. Sci. 2010, 118, 3066-3073.

[38] C. H. Chen, C. Y. Chen, Y. W. Lo, C. F. Mao, W. T. Liao, J. Appl. Polym. Sci. 2001, 80, 943-948.

[39] C. H. Chen, J. Appl. Polym. Sci. 2003, 87, 2004-2010.

[40] W. L. F. Armarego. D. D. Perrin, In Purification of Laboratory Chemicals, Butterworth-Heineman, Oxford, 1997. 


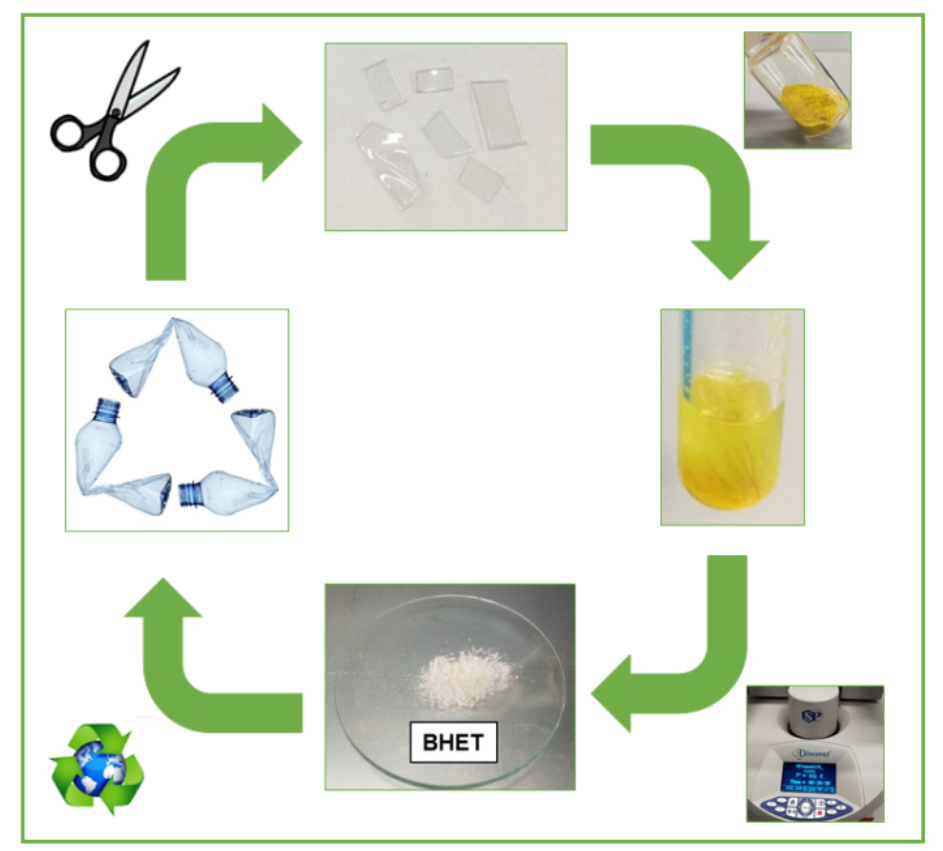

A new ionic liquid based on an imidazolium cation and an iron oxalate anion for the efficient glycolysis of polyethylene terephthalate (PET) under microwave and thermal heating conditions is reported here. The dielectric properties of the catalyst lead to a considerable reduction in reaction time when microwave irradiation is employed. This work provides valuable insights for the development of highly active, stable and recyclable catalysts for the efficient depolymerization of PET into highly pure monomers. 